\title{
Association between emotional intelligence and academic performance among students in Gandaki Medical College, Pokhara
}

\author{
Rami Shrestha1* (iD), Nirmala Shrestha², Sapana Koju¹, Ratna Keshari Tako³ \\ 'Department of Anatomy, Gandaki Medical College, '2Department of Community medicine, Gandaki Medical College, \\ ${ }^{3}$ Department of Physiology, Gandaki Medical College
}

\begin{abstract}
Introduction: Recent studies in last few decades are revealing that Intelligence Quotient (IQ) alone is not a reliable factor of students' academic achievement. It has been claimed that only $20 \%$ of a person's success can be attributed to IQ and rest 80\% to Emotional Quotient. Since, many researchers had claimed the influence of emotional intelligence on academic performance; the aims of this study were to find out the level of emotional intelligence and its relation with academic performance among Nepali undergraduate students. Methods: A cross sectional study was carried out in 280 medical students (120 male, 160 female). The data of this research was obtained through the use of a questionnaire which elicits information about their Emotional Intelligence level and academic performance. The obtained data was analyzed by SPSS. The degree of relationship between marks obtained and emotional intelligence were established by Correlation coefficient and Fischer exact test. The level of significance was set at p-value less than 0.05 . Results: The mean level of emotional intelligence was high $(5.055 \pm 0.798)$ among Nepalese medical students. The respondents were reported to have high level of emotional intelligence with $(5.544 \pm 0.929)$ for Self- awareness, $(5.035 \pm 1.01)$ for Social awareness, (5.394 \pm 1.11$)$ for Social skill and moderate level of emotional intelligence $(4.24 \pm 1.37)$ for Self-management. Conclusion: There was a positive and strong relationship between the respondents' overall emotional intelligence and their academic achievement which means that the higher their level of emotional intelligence, the better they perform academically.
\end{abstract}

Keywords: Academic performance, Emotional intelligence, Intelligence quotient

\section{*Correspondence:}

Ms. Rami Shrestha

Lecturer, Anatomy Department, Gandaki Medical College (Teaching Hospital and Research Center), Pokhara, Nepal

Email: ramistha2015@gmail.com

Submitted: November 2, 2020

Accepted: June 13, 2021

To Cite: Shrestha R, Shrestha N, Koju S, Tako RK. Association between emotional intelligence and academic performance among students in Gandaki Medical College, Pokhara. JGMC Nepal. 2021 June;14(1):29-32.

DOI: $10.3126 /$ jgmcn.v14i1.32622

Mobile number- +977-9841970206

\section{INTRODUCTION}

Peter Salovey and John D. Mayer (1990) defined "Emotional Intelligence" as "the subset of social intelligence that involves the ability to monitor one's own and others' feelings and emotions, to discriminate among them and to use this information to guide one's thinking and actions". ${ }^{1}$ In other words, it is an ability, capacity or skill to perceive, assess and manage the emotions of oneself, of others and of groups and an array of non-cognitive capabilities, competencies and skills that influences one's ability to succeed in coping with environmental demands and pressures. ${ }^{2}$ Daniel Goleman suggested Emotional competency as Self-awareness, Self-management, Social awareness and Social skills. Self-awareness is the ability to identify and name one's emotional states and to understand the link between emotions, thought and action. Self-management- The capacity to handle one's emotional states to shift undesirable emotional states to more adequate ones in order to improve and succeed. Social awareness- The ability to read, be sensitive and understand other peoples' emotions. Social Skills-The ability to interact in social situations to influence, persuade, negotiate and lead to sustaining satisfactory interpersonal 
relationship. ${ }^{2,3}$

Academic motivation is defined as the enthusiasm for academic achievement which involves the degree to which students possess certain specific behavioral characteristics related to motivation. ${ }^{4}$ Intelligence Quotient had always been used as a determinant of academic success. However, recent studies in the last few decades are revealing that IQ alone is not a reliable factor of students' academic achievement. Goleman (1995) claims that only $20 \%$ of a person's success can be attributed to IQ and the rest $80 \%$ to EQ. ${ }^{5}$ Students with low emotional intelligence show some adjustive challenges or fail to handle the demands of school work effectively in some way or the other. ${ }^{6,7}$ In other hand, students with emotional intelligence are able to control their emotions so that they are not carried away by the flow of negative elements. Therefore, they are confident enough to cope with demanding and complex college experience efficiently and can focus on their learning and perform academically. ${ }^{7-10}$

Since, many researchers had claimed the influence of emotional intelligence on academic performance, the aims of this study were to find out the level of emotional intelligence and its relation with academic performance among Nepali undergraduate students. Since the respondents were future medical professionals, it was insightful to establish whether emotional intelligence does help them perform academically.

\section{METHODS}

A cross-sectional study was conducted among 280 students (120 male \& 160 female), aged 18toto24 years, of Gandaki Medical College Teaching Hospital and Research Center (GMCTHRC), Pokhara. After obtaining clearance from Institutional Ethical Committee Ethical Committee of GMCTHRC, both genders of students from MBBS stream were approached for the study. The participants were given a brief explanation on the purpose of the study. Questionnaire was the sole instrument used for the purpose of data collection which consist of two Sections; Section A (Demographic Background) required participants to provide background information such as gender, age and marks obtained in higher secondary level and exams in undergraduate till date in percentage. Section B (Emotional Intelligence) consist of 16 items that attempt to measure students' level of Emotional Intelligence. This section was taken from the version adapted by Wong \& Law (2002) which consist of four dimensions which are Self-awareness, Social awareness, Self-management, Self-management and Social skills. Respondents were initially instructed on how to respond to the 7-point Likert scale items in order to make sure they understand what is expected of them and then asked to respond in which they had to rate their responses ranging from 1 which indicated Strongly Disagree to 7 which indicated Strongly Agree. They were given ample time to complete it and the questionnaire were collected on the same day to ensure high response rates. In this study, respondents' responses with a mean score of 0.00 to 2.99 was considered as Low, 3.00 to 4.99 as Moderate and that of 5.00 to 7.00 as High. Finally, all the data gathered were keyed-in and analyzed using SPSS (Statistical Package for Social Sciences) for statistical analysis. The degree of relationship between marks obtained and emotional intelligence were established by Correlation coefficient-coefficient and Fischer exact test. The level of significance was kept at $\mathrm{P}$ value less than 0.05 .

\section{RESULT}

Table 1: Distribution and percentage of respondents according to gender, age and Marks obtained in percentage $(n=280)$

\begin{tabular}{lcc}
\hline Respondent profile & Frequency & Percentage \\
Gender & 120 & \\
Male & 160 & 52.9 \\
Female & & 57.1 \\
Age & 180 & 64.3 \\
$18-20$ & 96 & 34.3 \\
$21-23$ & 4 & 1.4 \\
$\geq 24$ & 89 & 31.8 \\
Average marks obtained in Higher secondary level and MBBS exams till date \\
Low (50 \%-64.9\%) & 147 & 52.5 \\
Average (65\%-74.9\%) & 44 & 15.7 \\
High ( $\geq 75 \%)$ & & \\
\hline
\end{tabular}

Table 2: Descriptive analysis of domains of Emotional Intelligence

\begin{tabular}{lcc}
\hline Domains of Emotional Intelligence & Mean & Standard Deviation \\
Self-awareness & 5.544 & 0.929 \\
Social Awareness & 5.035 & 1.01 \\
Social Skill & 5.394 & 1.11 \\
Self-management & 4.24 & 1.37 \\
Average Emotional Intelligence & 5.055 & 0.798 \\
\hline
\end{tabular}

Table 2 presents overall mean score of emotional intelligence among the respondents. The study showed that the mean level of emotional intelligence is high among MBBS students of Gandaki Medical College, Pokhara, Nepal. 
Table 3: Correlation between Emotional Intelligence and Academic Achievement

\begin{tabular}{lll}
\hline & Rho value & Significance \\
Emotional intelligence & 0.236 & P value $<0.001$ \\
\hline
\end{tabular}

Significance at 0.05

Table 3 shows that there is a positive and strong relationship between the respondents' overall emotional intelligence and their academic achievement.

Table 4: Correlation between domains of emotional intelligence and Academic achievement

\begin{tabular}{lcc}
\hline Domains of emotional Intelligence & \multicolumn{2}{c}{ Spearman correlation (rho) } \\
Self-awareness & rho 0.092 & P value $=0.124$ \\
Social awareness & rho 0.173 & P value $=0.004$ \\
Social skill & rho 0.258 & P value $=<0.001$ \\
Self-management & rho 0.165 & P value $=0.006$ \\
\hline
\end{tabular}

Significance at 0.05

Table 5: Relationship between gender and Emotional Intelligence

\begin{tabular}{ccccc}
\hline \multirow{2}{*}{ Gender } & \multicolumn{3}{c}{ Emotional intelligence } & P value \\
& Low & Moderate & High & \\
Female & $2(1.3 \%)$ & $72(45 \%)$ & $86(53.8 \%)$ & \\
Male & $3(2.5 \%)$ & $34(28.3 \%)$ & $83(69.2 \%)$ & $0.015^{*}$ \\
\hline
\end{tabular}

*Fischer's exact test

This study showed significant association between gender and Emotional intelligence $(P$ value $=0.015)$.

\section{DISCUSSION}

Based on the findings of the study, the MBBS students of Gandaki Medical College, Pokhara have high level of emotional intelligence. It was found that there is a positive and strong relationship between the respondents' overall emotional intelligence and their academic achievement which means that the higher their level of emotional intelligence, the better they perform academically. As they are better motivated to handle, manage and control their emotions, they are more inclined to achieve academically. The above finding draws support from Maraichelvi ${ }^{1}$, Roy, ${ }^{13}$ Malik, $^{16}$ Jennabadi, ${ }^{12}$ and Carvalho. ${ }^{14}$ Studies by Nwadinigwe ${ }^{7}$ and Oyewunmi ${ }^{15}$ in Nigerian students and Mishra ${ }^{2}$ in Indian students also have consistent findings with this study. The result doesn't align with the finding of Malik ${ }^{11}$ in business students, Mohzan ${ }^{5}$ and Shah ${ }^{10}$ where they found either weak or negative correlation of emotional intelligence with academic performance.
In the present study, we also observed that female students are more emotionally intelligent than male students. That means female students are more capable to manage their emotions and cope up with stress that arise in academic fields. It disagrees with the findings of Jennabadi ${ }^{12}$ and Malik ${ }^{16}$ who reported that there is no gender difference in emotional intelligence.

\section{CONCLUSION}

The study showed future doctors of Gandaki Medical College, Pokhara, Nepal have high level of emotional intelligence. It was found that there is a strong positive relationship between the respondents' overall emotional intelligence and their academic achievement. It can be concluded that developing and focusing on emotional intelligence of students will definitely lead to enhancement of their academic achievements. Moreover, female students are more capable to manage their emotions and cope up with stress that arise in academic fields.

Conflict of interest: Authors declare no conflict of interest.

\section{REFERENCES}

1. Maraichelvi A, Rajan S. The Relationship between Emotional Intelligence and the Academic Performance among Final Year under Graduates. Universal Journal of Psychology. 2013;1(2):41-5. DOI: 10.13189/ujp.2013.010203

2. Mishra P. A Study of the Effect of Emotional Intelligence on Academic Achievement of Jaipur Senior Secondary Students. Int J of Educational Research and Tech. 2012;3(4):25-8. DOI: 10.24924/ijabm/2016.04/v4.iss1/10.18

3. Goleman D. Emotional intelligence. Why it matters more than IQ. Learning, 1996;24(6):24-5.

4. Hwang YS, Echols C, Vrongistinos K. Multidimensional academic motivation of high achieving African American students. College Student Journal. 2002;36(4):544-54. DOI: 10.5829/idosi.mejsr.2016.24.03.22452

5. Mohzan MAM, Hassan N, Halil NA. The Influence of Emotional Intelligence on Academic Achievement. Procedia - Social and Behavioral Sciences. 2013;90:303-12. DOI: 10.1016/j. sbspro.2013.07.095

6. Oyinloye JMA. Emotional Intelligence. An introduction to general psychology and pastoral counselling. Lagos: Emaphine Reprographics Ltd; 2005.

7. Nwadinigwe IP, Azuka-Obieke U. The Impact of Emotional Intelligence on Academic Achievement of Senior Secondary School Students in Lagos, Nigeria. JETERAPS. 2012;3(4):395401. DOI: 10.12691/education-6-7-25

8. Yahaha A, Ee NS, Bachok JDJ, Yahaya N, Boon Y, Hashim S, 
et al. The Impact of Emotional Intelligence Element on Academic Achievement. Archives Des Sciences. 2012;65(4):117.

9. Low GR, Nelson, DA. Emotional Intelligence effectively bridging the gap between high school and college. Texas Study Magazine for Secondary Education, Spring Edition. 2004

10. Shah CJ, Sanisara M, Mehta HB, Vaghela HM. The relationship between emotional intelligence and academic achievement in medical undergraduate. Int J Res Med Sci. 2014;2(1):5961. DOI:10.5455/2320-6012.IJRMS20140211

11. Malik SZ, Sehrish S. Effect of Emotional Intelligence on Academic Performance among Business Students in Pakistan. Bulletin of Education and Research. 2016;38(1):197-208.

12. Jenaabadi H, Shahidi R, Elhamifar A, Khademi H. Examine the Relationship of Emotional Intelligence and Creativity with Academic Achievement of Second Period High School Students. World J of Neuroscience. 2015;5:275-81. DOI:dx. doi.org/10.3126/ijls.v9i6.12684
13. Roy B, Sinha R, Suman S. Emotional Intelligence and Academic Achievement Motivation among Adolescent: A Relationship study. Int Refereed Research J. 2013;4(2):126-30. Corpus ID: 140859877

14. Carvalho J, Colvin AD. Emotional Intelligence and Academic Success among Low Income College Students. International Journal of Education and Social Science. 2015;2(3):35-42.

15. Oyewunmi AE, Osibanjo AO, Adeniji AA. Emotional Intelligence and Academic Performance of Undergraduates: Correlations, Implications and Interventions. Mediterranean Journal of Social Sciences. 2016;7(1):509-16. DOI: 10.5901/ mjss.2016.v7n1p509

16. Malik F, Shujja S. Emotional Intelligence and Academic Achievement: Implications for Children's Performance in Schools. Journal of the Indian Academy of Applied Psychology. 2013;39(1):51-9. DOI: http://dx.doi.org/10.6000/19275129.2016 .12 .53 